\title{
C-K Design Theory for Information Systems Research
}

\author{
Jan Ondrus \\ ESSEC Business School \\ Av. Bernard Hirsch \\ 95021 Cergy Pontoise, France \\ ondrus@essec.fr
}

\author{
Yves Pigneur \\ Faculty of Business and Economics (HEC) \\ University of Lausanne \\ 1015 Lausanne, Switzerland \\ yves.pigneur@unil.ch
}

\begin{abstract}
Design science is slowly but surely establishing itself as a recognized paradigm for conducting research in information systems. Researchers in the IS field have tried to study different aspects of design science. So far, it seems that the design activity, or "design reasoning" has not received much attention from the IS community. In this paper, we propose to use a theory developed in engineering fields in order to solve this issue. The $C$ - $K$ theory, or Concept-Knowledge theory, is considered to be a good candidate to deal with the design reasoning.
\end{abstract}

\section{Categories and Subject Descriptors}

H.4 [Information Systems Applications]: Miscellaneous

\section{General Terms}

Design science

\section{Keywords}

Design reasoning, design theory, design rationale

\section{INTRODUCTION}

Recent literature on design science research in IS and other IS design theories consider the design product, the design process, and the design environment in IS design research. However, most authors gave less attention on the design activity itself, or "design reasoning".

Design science refers to a rational approach to design, with an explicit design reasoning for determining and categorizing the properties of the designed system and the design process, as already suggested by Hubka and Eder [3] in engineering. In research, design reasoning has to especially explicit the role of the theoretical knowledge in deriving information suitable for the design, and reversely the creation of theoretical knowledge issued from the design. It has been recognized that IS design research can mature by assimilating the relevant research and philosophical discussions of

Permission to make digital or hard copies of all or part of this work for personal or classroom use is granted without fee provided that copies are not made or distributed for profit or commercial advantage and that copies bear this notice and the full citation on the first page. To copy otherwise, to republish, to post on servers or to redistribute to lists, requires prior specific permission and/or a fee.

DESRIST 09, May 7-8, 2009, Malvern, PA, USA

Copyright 2009 ACM 978-1-60558-408-9/09/05 ...\$5.00. older design fields, especially with relation to theory in design fields. The claim made by these authors motivated our research effort presented in this paper.

Our research question is to explain and justify that a theory developed in the engineering field (i.e., $C$-K theory [1]), based on the tension between "concepts" and "knowledge", is a good candidate for dealing with design reasoning, and the relationship between design and knowledge in IS design research.

\section{DESIGN SCIENCE}

Different aspects of design science in IS research have been considered in the literature: framework and guidelines, taxonomy and theory, method and process, paradigms and theses, and patterns. However few of them consider the design activity itself and "design reasoning".

In a way, what we call "design reasoning" has similarities with "design rationale" in software engineering, defined as an explanation of why an artifact is designed the way it is [4]. However, in "design rationale", the link between design and knowledge which has to be taken into consideration in research is usually not explicitly covered.

Therefore, we suggest the proposition that design science research in the information systems discipline needs a theory or a model to deal with "design reasoning", and the relationship between design and (theoretical) knowledge.

\section{C-K THEORY}

$C-K$ theory is a unified design theory introduced in engineering by Hatchuel et al. [1]. The name reflects the assumption made by the authors that design can be modelled and analyzed as the interplay between two interdependent spaces: the space of concepts (C) and the space of knowledge $(\mathrm{K})$.

To justify the usage of the C-K theory, the authors expose the limits of the usual "mapping design theories", which define design as a mapping process between functions and design parameters or structures". They show the importance to capture the generation of new objects and new knowledge, which are distinctive features of design. They underline a fundamental property of design, which is that "design cannot be defined without a simultaneous knowledge expansion process".

In this theory, the starting point of a design project (or research) is the formulation of an idea, a specification, a "concept", which is an incomplete or ambiguous set of desired properties qualifying the object (in IS, we commonly use the term: artefact) to be designed. 
The theory assumes a space of knowledge $(\mathrm{K})$, which is the established knowledge available to a designer and contains propositions of partly known objects as well as relations between these objects. Propositions have a logical status (true or false in classic logic, non standard logic could be adopted as well). $\mathrm{K}$ is expandable since its content changes over time.

A "concept" is a proposition implying that "an object verifies a group of properties". A concept has no logical status in the space of knowledge $(\mathrm{K})$. In fact, when a concept is proposed, it is not possible to prove that it is a proposition of K. Concepts are considered as sets that can only be partitioned or included (not searched). If a property is added, the set is partitioned in subsets. If a property is removed, the set is included in a set that contains it. The process of adding and removing properties to or from concepts is the central mechanism for the design reasoning activity. The space of concepts (C) has a tree structure based on these partitions and inclusions.

Four operators have been defined, represented in the socalled "design square" (see Figure 1):

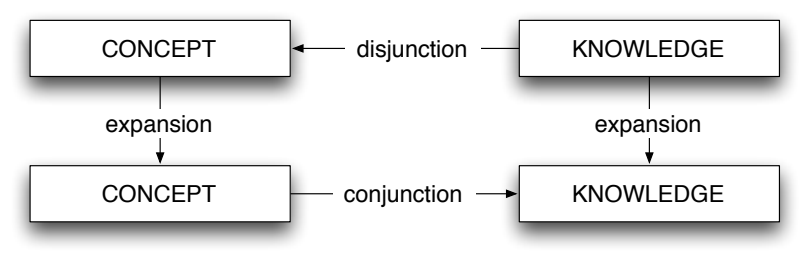

Figure 1: C-K design square from Hatchuel et al. [2]

$K \rightarrow C$ operator: this operator adds or removes properties from K to concepts in C. It creates "disjunctions" when it transforms a proposition into a concept. This corresponds to the generation of alternatives. It expands the space $\mathrm{C}$ with elements from $\mathrm{K}$.

$C \rightarrow K$ operator: this operator seeks for properties in $\mathrm{K}$ that could be added or removed to reach propositions with a logical status. It creates "conjunctions" which could be accepted as finished design. This corresponds to evaluation using an experimental plan, a prototype, or testing. It expands knowledge with the help of concepts.

$C \rightarrow C$ operator: this operator controls the expansion of the space or tree of concepts, by partition or inclusion.

$K \rightarrow K$ operator: this operator allows to expand the space of knowledge using logic and proving new theorems.

The expansion mechanisms help to define design as "the reasoning activity which starts with a concept about a partially unknown object and attempts to expand it into other concepts and/or to generate new knowledge". Design generates the co-expansion of the two spaces: design is the process by which $K \rightarrow C$ disjunctions are generated, then expanded by partition or inclusion, to reach $C \rightarrow K$ conjunctions.

\section{APPLICATION OF THE C-K THEORY}

To illustrate and validate the $C$ - $K$ theory applied to IS research, we use a recent research [5], which objective was to design a systematic approach to analyze rigorously the mobile payment market and its potential disruptiveness. We wanted to seek a better understanding of the reasons for the delayed deployment of mobile payments in Switzerland. In order to achieve this objective, we formulated and explored the hypothesis that multi-criteria decision-making (MCDM) methods were suitable for strategic technology assessment and foresight. Following this claim, we adopted an MCDM approach to design artefacts.

Using the $C-K$ theory, an expansion tree of concepts, disjunctions and conjunctions have been built for designing and evaluating prototypes. The addition to the knowledge base or "conjunction" established that an MCDM approach is appropriate for technology foresight and disruption analysis, confirming the hypothesis initially suggested by Salo et al. [6]

\section{CONCLUDING REMARKS}

The application of the $C$ - $K$ theory demonstrated several benefits in order to better describe the design reasoning done during a research project. The interplay between the space of concepts and space of knowledge is quite informative. In fact, by decomposing the different decisions taken into concepts, we were able to reconstruct the reasoning behind the design and reflect about the research choices. Moreover, we reached a better visualization of what knowledge elements are involved at each stages.

We used the $C$ - $K$ theory on past research to illustrate the instantiation of the theory. We claim the $C$ - $K$ theory can also be used during the research development to guide the design process and capture the design reasoning. By doing this, researchers obtain a good representation of their actual design decisions and could be used as a design logbook. This mapping can also assist researchers to explore different avenues by testing different opposed concepts. More than just guidance, the $C$ - $K$ theory can be used support the justification of design choices.

In this essay, we covered two of the loops proposed by Hevner et al. [2]. One is the loop of the design process (i.e., build and evaluate) and the other one is the loop of the contributions to the body of knowledge after each design iterations. By using the $C-K$ theory we explicitly represent the synchronization of the loops. Both loops are integrated using the four operators of the $C$ - $K$ theory, and its explicit links between the concepts and knowledge elements.

\section{REFERENCES}

[1] A. Hatchuel and B. Weil. A new approach of innovative design: an introduction to $\mathrm{C}-\mathrm{K}$ theory. In Proceedings of the international conference on engineering design (ICED'03), pages 109-124, 2003.

[2] A. Hevner, S. March, J. Park, and S. Ram. Design science in information system. MIS Quarterly, 28(1):75-105, 2004.

[3] V. Hubka and W. Eder. A scientific approach to engineering design. Design studies, 8(3):123-137, 1987.

[4] J. Lee. What's in design rationale? Human-Computer Interaction, 6:251-280, 1991.

[5] J. Ondrus and Y. Pigneur. Cross-industry preferences for mobile payments development in switzerland. Electronic Markets - The International Journal, 17(2):246-257, May 2007.

[6] A. Salo, T. Gustafsson, and R. Ramanathan. Multicriteria methods for technology foresight. Journal of Forecasting, 22(2):235-255, 2003. 